\title{
Non-Hispanic Black-White disparities in pain and pain management among newly admitted nursing home residents with cancer
}

This article was published in the following Dove Press journal: Journal of Pain Research

\author{
Deborah S Mack' \\ Jacob N Hunnicutt ${ }^{\prime}$ \\ Bill $M$ Jesdale ${ }^{2}$ \\ Kate L Lapane ${ }^{2}$
}

'Department of Quantitative Health Sciences, Clinical and Population Health Research Program, Graduate School of Biomedical Sciences, University of Massachusetts Medical School, Worcester, MA, USA; ${ }^{2}$ Department of Quantitative Health Sciences, University of Massachusetts Medical School, Worcester, MA, USA

Correspondence: Kate L Lapane Department of Quantitative Health Sciences, University of Massachusetts Medical School, 368 Plantation Street, Worcester, MA 01605, USA

Tel + I 5088568993

Email Kate.Lapane@umassmed.edu
Background: Racial disparities in pain management persist across health care settings and likely extend into nursing homes. No recent studies have evaluated racial disparities in pain management among residents with cancer in nursing homes at time of admission.

Methods: Using a cross-sectional study design, we compared reported pain and pain management between non-Hispanic White and non-Hispanic Black newly admitted nursing home residents with cancer $(n=342,920)$ using the de-identified Minimum Data Set version 3.0. Pain management strategies included the use of scheduled analgesics, pro re nata analgesics, and nonpharmacological methods. Presence of pain was based on self-report when residents were able, and staff report when unable. Robust Poisson models provided estimates of adjusted prevalence ratios (aPR) and 95\% CIs for reported pain and pain management strategies.

Results: Among nursing home residents with cancer, $\sim 60 \%$ reported pain with non-Hispanic Blacks less likely to have both self-reported pain (aPR [Black versus White]: $0.98,95 \% \mathrm{CI}$ : 0.97-0.99) and staff-reported pain (aPR: 0.89, 95\% CI: 0.86-0.93) documentation compared with Non-Hispanic Whites. While most residents received some pharmacologic pain management, Blacks were less likely to receive any compared with Whites (Blacks: 66.6\%, Whites: 71.1\%; aPR: 0.98, 95\% CI: 0.97-0.99), consistent with differences in receipt of non-pharmacologic treatments (Blacks: 25.8\%, Whites: 34.0\%; aPR: 0.98, 95 CI\%: 0.96-0.99).

Conclusion: Less pain was reported for Black compared with White nursing home residents and White residents subsequently received more frequent pain management at admission. The extent to which unequal reporting and management of pain persists in nursing homes should be further explored.

Keywords: nursing homes, cancer, pain, pain management, race

\section{Introduction}

One in 10 nursing home residents have cancer. ${ }^{1}$ Among those with cancer, the frequency of any type of pain (often considered "the fifth vital sign"" $)$ ranges from $37 \%$ to $66 \%,{ }^{1,3-7}$ of which about $75 \%$ is moderate-to-severe. ${ }^{1}$ Nursing home residents with cancer are also twice as likely to have daily pain that is at times excruciating than those without cancer. ${ }^{8}$ This population needs effective pain management strategies to relieve suffering and ensure dignity in care. ${ }^{9}$ The application of existing clinical practice guidelines can effectively manage pain in the vast majority ${ }^{10}$ of all patients. ${ }^{11-13}$

Racial disparities in the treatment of pain persist. ${ }^{14-18}$ Among older patients, racial/ ethnic minorities have poorer pain management than their non-Hispanic white counterparts across multiple health care settings. ${ }^{1,6,7,19-23}$ In nursing homes, and especially among those with cancer, relative to Whites, Blacks are at increased risk for under- 
reporting and treatment of pain. ${ }^{1,7}$ The few related studies available are limited in that the relationship between race and pain was only evaluated secondarily within a larger objective of assessing general pain management and was done so with data collected decades ago. With a high frequency of pain in the nursing home population with cancer, racial disparities in pain reporting and management could have a profound effect on the quality of life. A thorough and updated evaluation of these disparities is warranted.

We conducted a contemporary evaluation of Black-White disparities in pain reporting and its management among residents with cancer at the time of nursing home admission nationwide. We hypothesized that the prevalence of documented pain would be lower in non-Hispanic Black residents when compared with non-Hispanic White residents. We also hypothesized that the prevalence of pain management would be lower in non-Hispanic Black residents than non-Hispanic White residents. Recognizing this disparity is an important first step to work toward improving nursing home treatment and care.

\section{Methods}

\section{Study design}

This cross-sectional study used national and comprehensive data from the Minimum Data Set (MDS) 3.0 to assess pain reporting and management at nursing home admission between non-Hispanic Black and non-Hispanic White residents. The MDS 3.0 is an improved version of the MDS 2.0 and is conducted in all Medicare-/Medicaid-certified nursing facilities. The MDS data were de-identified. The MDS is completed with all available information, including medical records, transfer records, hospital discharge information, and self-reported information. This study was approved by the University of Massachusetts Medical School Institutional Review Board.

\section{Data source}

The MDS 3.0 is a validated ${ }^{24}$ and reliable administrative assessment that is required in all Medicaid- and Medicarecertified facilities ( $\sim 96 \%$ of all nursing homes). Assessments are conducted by trained health care providers who interview residents (if they are able to self-report), their family members or other proxies, and direct care staff at nursing home admission and at 90-day intervals thereafter; assessments collect information on resident sociodemographic characteristics, clinical measures, functional status, cognitive patterns, diagnoses, treatments, and procedures. We used information only from admission MDS assessments.

\section{Sample selection}

From 3,748,663 newly admitted nursing home residents with MDS 3.0 assessments performed between January 1, 2011 and December 31, 2012 (Figure 1), we identified 402,323 residents with an MDS active cancer diagnosis; ${ }^{25} 371,169$ residents were non-Hispanic Black or non-Hispanic White. We included those aged $\geq 50$ years old, non-comatose, and those without missing information on covariates (except source of admission). The admission assessment is required by day 14 in the nursing home. Residents whose admission assessment was completed in $>21$ days were excluded. The final sample consisted of 342,920 residents.

\section{Outcome measures}

We considered 2 domains: documentation of pain and management of pain.

\section{Reported pain}

The MDS 3.0 includes a pain section (Section $\mathrm{J}^{26}$ ) prompted by a requirement to document any self-reported (or if unable to self-report, staff-assessed) pain during the 5 days prior to the assessment. The self-reported pain assessment includes items that measure any pain (yes/no), pain frequency (rarely, occasionally, frequently, and almost constantly), pain effects on function (pain made it hard to sleep [yes/no], has pain limited day-to-day activities [yes/no]) and pain intensity (either numeric scale: 0 [none] to 10 [worst] pain or verbal descriptor scale: mild, moderate, severe, or very severe pain). Following the method of Edelen and Saliba, pain intensity variables were combined into 1 variable, pain severity, which classified pain into 4 levels: mild, moderate, severe, or very severe. ${ }^{24,27}$ For those unable to self-report pain, staff assessed a resident's pain based on observation and/or medical records with items that measure any pain (yes/no) and its frequency in the past 5 days (none, $1-2$ days, 3-4 days, and daily). ${ }^{26}$

\section{Pain management}

Using information in the medical record, pain management strategies were documented among all residents because of the cross-sectional nature of the data and the MDS instructions given to record pain. For example, if pain was wellcontrolled, the MDS pain variable would be coded as "No pain present". We evaluated if a resident received any pain medication in the past 5 days from the MDS 3.0 Section $\mathrm{J}^{26}$ using the items that ask if the resident is on a scheduled pain medication, has received their pharmacological pain medication, or has a non-medication intervention for pain. If a resident is unable to self-report pain, staff members 


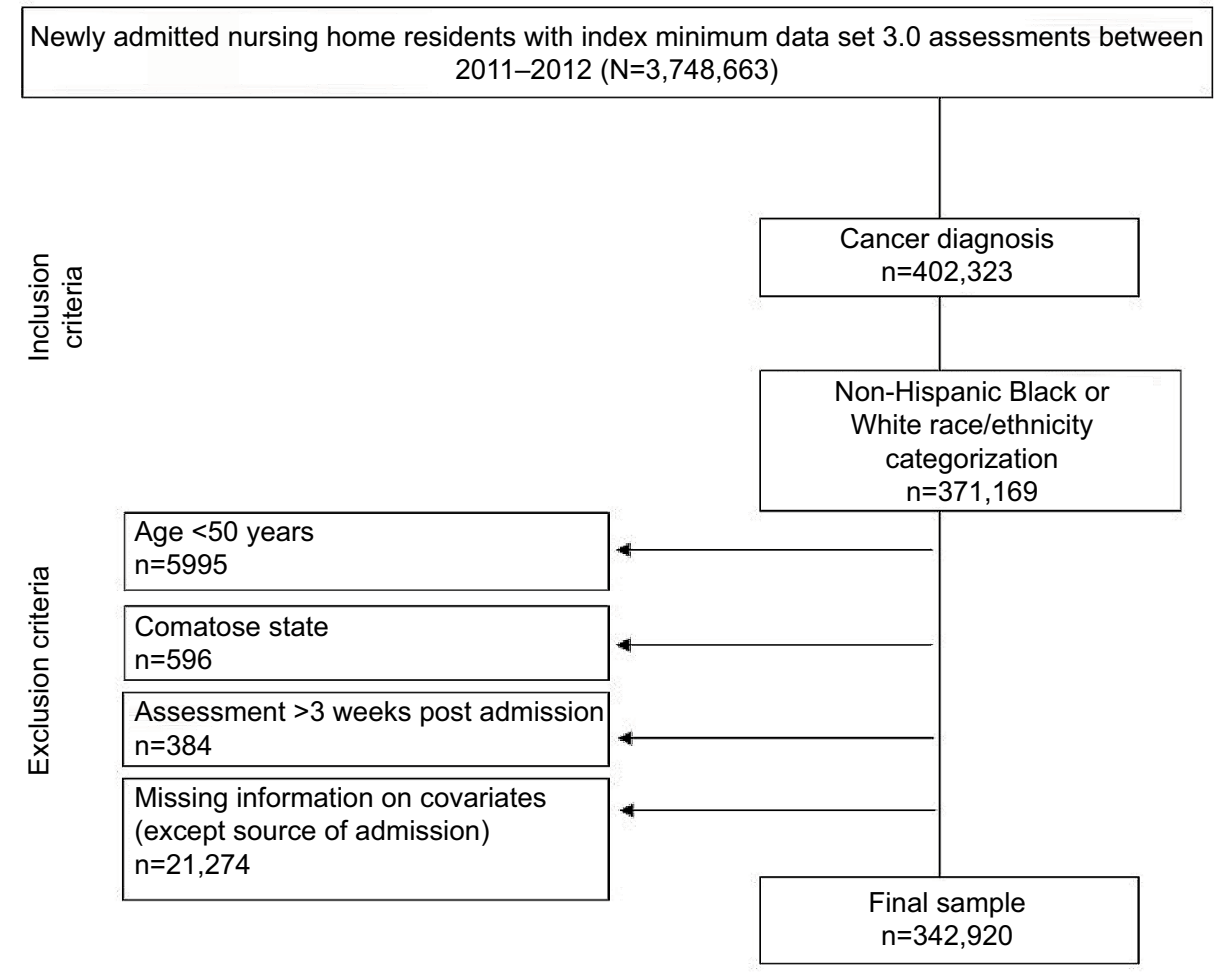

Figure I Study sample selection consort among newly admitted nursing home residents.

are instructed to document pain medication status based on review of information in their medical record. Two pain management variables were binary (yes/no) receipt of: any pharmacologic treatment (scheduled and/or pro re nata (PRN) medications) and any non-pharmacologic pain treatment. We also created a 4-level variable: 1) receipt of both scheduled and PRN analgesics (if both were coded as yes, then residents were placed in this category); 2) scheduled pain regimen alone (if scheduled pain regimen was coded as yes, but PRN coded as no, then residents were placed in this category); 3 ) PRN analgesics alone (if PRN was coded as yes, but scheduled pain regimen coded as no, then residents were placed in this category); and 4) no receipt of pharmacologic pain medications (if scheduled pain regimen and PRN were both coded as no, then residents were placed in this category).

\section{Measure of race}

Race/ethnicity was documented in Section $\mathrm{A}^{28}$ of MDS 3.0. When completing an admission assessment, health care providers were instructed to record race/ethnicity of nursing home residents (via self-report, health care proxy-report if self-report not possible, or perceived if neither) with 1 or more of the following categories: White, Black or AfricanAmerican, Hispanic or Latino, Asian, American Indian/ Alaskan Native, or Native Hawaiian/Pacific Islander. We included residents classified as non-Hispanic Black or nonHispanic White (reference group). Nursing home residents with multiple categories of race/ethnicity documented were not included. We did so to facilitate comparison with previous literature on this topic. ${ }^{14,21}$ These studies have mostly considered non-Hispanic Blacks to be the "exposed" group and non-Hispanic Whites to be the reference group. ${ }^{14,17,21,29}$

\section{Covariates}

The variables were included as potential confounders based on evidence that suggested that they may be associated with reporting of pain or receiving pain medications. ${ }^{1,7}$ Sociodemographic characteristics included gender, age (50-64, 65-74, 75-84, and $\geq 85$ years), and marital status (married, not married, or separated). Resident care or status variables included receiving skilled nursing care indicated by receipt of a Skilled Nursing Facility Prospective Payment System assessment, source of admission (community [i.e., private residence, board/care, assisted living, or group home], another nursing home or swing bed, acute hospital, psychiatric hospital, inpatient rehabilitation facility, hospice, or other), rejects care (e.g., medications and bloodwork), hospice use (within the last 14 days either as a resident or prior to being a resident), and 6-month or less prognosis (excluding those on hospice). Physical and cognitive 
impairment measures included Activities of Daily Living (ADLs) limitations (minimal, moderate, and severe) and cognitive impairment (none/mild, moderate, and severe). ADL limitations were based on the MDS ADL Self-Performance Hierarchy ${ }^{30}$ scored from 0 to 6 and categorized as the following: 0-2 as none/mild, 3-4 as moderate, and 5-6 as severe ADL limitations. Cognitive impairment was based on the Cognitive Function Scale, ${ }^{31}$ which is primarily based on the self-reported Brief Interview for Mental Status (BIMS); if the residents were unable to complete the BIMS, the staffassessed Cognitive Performance Scale (CPS) was used. The cognitive impairment variable was grouped into 3 levels of impairment based on the BIMS score, which ranges from 0 to 15 (13-15: none/mild, 8-12: moderate, and 0-7: severe) and the CPS score, which ranges from 0 to $6(0-2$ : none $/ \mathrm{mild}$, 3-4: moderate, and 5-6: severe). Mental health conditions included the presence (or absence) of the following variables: dementia (or Alzheimer's disease), depression (other than bipolar), and anxiety disorder. Painful comorbid conditions included heart failure, respiratory failure, inflammatory bowel disease, arthritis, osteoporosis, fracture (hip and other), and skin lesions/infections (unhealed pressure ulcers, surgical wounds, wound infection, second-/third-degree burns, open lesions, infection of the food, diabetic foot ulcer, and other open lesion on the foot), Parkinson's disease, and multiple sclerosis. Painful morbidities, such as inflammatory bowel disease, Parkinson's disease, and multiple sclerosis were included because of the high prevalence of reported pain among those with these conditions. ${ }^{32-34}$ Table S1 shows the specific MDS item numbers used to define these variables.

\section{Statistical analyses}

We used descriptive statistics to describe the sample with the following types of variables: sociodemographic, resident care/status, physical/cognitive impairment, and painful comorbid conditions. Reported pain was analyzed stratified by self-reported versus staff-reported assessment method. Modified Poisson models (implemented with generalized estimating equations using an exchangeable correlation structure to account for clustering within nursing facilities) were used to provide estimates of prevalence ratios ${ }^{35,36}$ and $95 \%$ CIs comparing non-Hispanic Black with non-Hispanic White (reference) reported pain and pain management strategies. Adjusted prevalence ratios (aPR) and corresponding 95\% CIs were derived from models with all covariates described previously with the exception of variables for admission source and receipt of skilled nursing care. A similar modeling approach was used to compare pain management strategies with separate modified Poisson models for the 2 binary pain management variables (any pharmacologic and any nonpharmacologic treatments) and a multinomial model for the 4-level type of pharmacologic treatment variable (using no pharmacologic treatment as the reference group).

\section{Results}

\section{Study population}

The mean age was $80.5 \pm$ SD 9.7 years among non-Hispanic White nursing home residents and 75.0 ( \pm SD 11.2) years among non-Hispanic Black residents (Table 1). While 38.6\% of non-Hispanic White residents were married at entry to nursing home, $27.5 \%$ of non-Hispanic Black residents were married. Consistent across race, most residents entered the nursing home from an acute care hospital. More than threequarters of all residents had moderate or severe limitations in ADLs (Whites: $82.9 \%$, Blacks: $84.2 \%$ ), while many also had moderate or severe cognitive impairment (Whites: $39.0 \%$, Blacks: $46.8 \%$ ). The prevalence of painful conditions appeared to be similar by race/ethnicity as the prevalences did not exceed an absolute difference of $>5 \%$. Only a fraction of the population had osteoporosis, with apparent differences between non-Hispanic Whites and non-Hispanic Blacks.

\section{Reports of pain}

Among nursing home residents with cancer who were able to self-report pain (Table 2), non-Hispanic Blacks had pain recorded less frequently than non-Hispanic Whites (Black: 58.1\%, White: $62.3 \%$; aPR Black relative to White: 0.98 , 95\% CI: 0.97-0.99). Among newly admitted residents with cancer, $10.3 \%$ of non-Hispanic Black residents and $7.8 \%$ of non-Hispanic White residents were unable to self-report pain and as a result, had staff-reported pain. Among those who were unable to self-report, $46.2 \%$ of non-Hispanic Black residents and $54.8 \%$ of non-Hispanic White residents had staff-documented pain (aPR Black relative to White: 0.89 , 95\% CI: 0.86-0.93).

The MDS included additional pain measures (albeit different for those self- versus staff-pain assessments) for those with documented pain. Among those with any self-reported pain $(n=194,920)$, pain frequency was similar between nonHispanic Blacks and non-Hispanic Whites with $13 \%$ of all residents reporting almost constant pain (Blacks: $12.6 \%$, Whites: $13.3 \%$ ), $\sim 37 \%$ reporting frequent pain (Blacks: $37.2 \%$, Whites: $37.8 \%$ ), and $\sim 42 \%$ reporting occasional pain (Blacks: $43.5 \%$, Whites: $41.9 \%$ ). Pain severity was similar by race. Among non-Hispanic Black residents, $8.3 \%$ reported very severe, horrible pain; $23.6 \%$ reported severe pain; $47.1 \%$ 
Table I Characteristics of nursing home residents with cancer at admission by race $(n=342,920)$

\begin{tabular}{|c|c|c|}
\hline Resident characteristics & $\begin{array}{l}\text { Non-Hispanic } \\
\text { Black, } \\
n=39,08 \text { I }\end{array}$ & $\begin{array}{l}\text { Non-Hispanic } \\
\text { White, } \\
n=303,839\end{array}$ \\
\hline Sociodemographic & Percentage & \\
\hline \multicolumn{3}{|l|}{ Age group, years } \\
\hline $50-64$ & 21.6 & 10.5 \\
\hline $65-74$ & 29.0 & 20.8 \\
\hline $75-84$ & 31.9 & 36.5 \\
\hline $85+$ & 17.5 & 32.2 \\
\hline Women & 47.4 & 53.3 \\
\hline Married & 27.5 & 38.6 \\
\hline \multicolumn{3}{|l|}{ Resident care/status } \\
\hline Receiving skilled nursing care & 63.3 & 70.8 \\
\hline \multicolumn{3}{|l|}{ Source of admission ${ }^{\mathrm{a}}$} \\
\hline Community & 4.4 & 6.8 \\
\hline $\begin{array}{l}\text { Another nursing home or swing } \\
\text { bed }\end{array}$ & 2.8 & 3.0 \\
\hline Acute hospital & 90.9 & 87.9 \\
\hline Psychiatric hospital & 0.3 & 0.3 \\
\hline Inpatient rehabilitation facility & 0.6 & 0.8 \\
\hline Hospice & 0.8 & 0.9 \\
\hline Other & 0.3 & 0.3 \\
\hline Rejects care & 7.7 & 7.1 \\
\hline Hospice use & 7.4 & 7.3 \\
\hline Six month or less prognosis & 6.1 & 7.2 \\
\hline \multicolumn{3}{|l|}{ Limitations in activities of daily living } \\
\hline Minimal & 15.8 & I7. \\
\hline Moderate & 49.2 & 57.5 \\
\hline Severe & 35.0 & 25.4 \\
\hline \multicolumn{3}{|l|}{ Cognitive impairment } \\
\hline None/mild & 53.2 & 61.0 \\
\hline Moderate & 27.0 & 24.2 \\
\hline Severe & 19.8 & 14.8 \\
\hline \multicolumn{3}{|l|}{ Painful comorbid conditions } \\
\hline Heart failure & 16.9 & 17.6 \\
\hline Respiratory failure & 3.0 & 2.6 \\
\hline Inflammatory bowel disease & 0.8 & 1.4 \\
\hline Arthritis & 19.3 & 24.3 \\
\hline Osteoporosis & 4.1 & 11.0 \\
\hline Fracture (hip and other) & 5.8 & 13.4 \\
\hline Skin lesions/infections/ulcers & 42.7 & 45.4 \\
\hline Parkinson's disease & 1.8 & 3.1 \\
\hline Multiple sclerosis & 0.3 & 0.4 \\
\hline
\end{tabular}

reported moderte pain; and $20.9 \%$ reported mild pain. Among non-Hispanic White residents, $7.2 \%$ reported very severe, horrible pain; $22.4 \%$ reported severe pain; $47.9 \%$ reported moderte pain; and $22.5 \%$ reported mild pain. Reports that pain caused sleep difficulties (Blacks: 27.8\%; Whites: 29.4\%) and limited day-to-day activities (Blacks: $38.2 \%$; Whites: $40.8 \%$ ) were common. Among those with any staff-reported pain $(n=14,896)$, in the past 5 days, $31.7 \%$ of non-Hispanic Black residents and $35.7 \%$ of non-Hispanic White residents had daily pain documented and $30.1 \%$ of non-Hispanic Black residents and $30.9 \%$ of non-Hispanic White residents had 3-4 days of pain documented.

\section{Pain management}

While most residents received some pharmacologic pain management (Table 3), non-Hispanic Blacks were less likely to receive any compared with non-Hispanic Whites (Blacks: 66.6\%, Whites: $71.1 \%$; aPR: 0.98, 95\% CI: 0.97-0.98). With respect to the pharmacologic pain regimen, non-Hispanic Blacks were less likely than non-Hispanic Whites to receive PRN medications (aPR: 0.84, 95\% CI: 0.81-0.87), and scheduled + PRN medications (aPR: 0.81, 95\% CI: 0.78 0.84). Non-Hispanic Blacks were also less likely to receive non-pharmacologic treatment for pain than non-Hispanic Whites (Blacks: 25.8\%, Whites: 34.0\%; aPR: 0.98; 95 CI\%: 0.96-0.99).

\section{Discussion}

Non-Hispanic Black residents were admitted to nursing homes at a younger age than non-Hispanic White residents. Severe ADLs and cognitive impairments appeared to be more prevalent in non-Hispanic Black residents relative to non-Hispanic Whites. Regardless of race, most were admitted from acute care hospitals and few were enrolled in hospice. We found that pain was common among nursing home residents with cancer, yet non-Hispanic Black residents were less likely to have both self- and staff- reported pain

Table 2 Reporting of pain in the last 5 days among nursing home residents with cancer at admission by race/ethnicity and self- versus staff-reported pain $(n=342,920)$.

\begin{tabular}{|c|c|c|c|c|}
\hline Reporting of pain & Non-Hispanic Black & Non-Hispanic White & $\begin{array}{l}\text { Crude prevalence } \\
\text { ratio }^{\mathrm{a}}(95 \% \mathrm{Cl})\end{array}$ & $\begin{array}{l}\text { Adjusted prevalence } \\
\text { ratio }^{\text {b }}(95 \% \mathrm{Cl})\end{array}$ \\
\hline \multirow[t]{2}{*}{ Self-reported pain assessment $(n=3|5| 0 \mid)}$, & $n=35,066$ & $\mathrm{n}=280,035$ & - & - \\
\hline & Percentage & & & \\
\hline Any pain & 58.1 & 62.3 & $0.96(0.95-0.97)$ & $0.98(0.97-0.99)$ \\
\hline \multirow[t]{2}{*}{ Staff pain assessment $(n=27,819)$} & $n=4015$ & $n=23,804$ & - & - \\
\hline & Percentage & & & \\
\hline Any pain & 46.2 & 54.8 & $0.89(0.86-0.93)$ & $0.89(0.86-0.93)$ \\
\hline
\end{tabular}

Notes: aPrevalence ratio estimated via robust Poisson modeling with facility clustering accounted for with a generalized estimating equations (GEE) approach. ${ }^{b}$ Adjusted prevalence ratios derived from models including all characteristics in Table I except variables for receipt of skilled nursing care and source of admission. 
Table 3 Management and treatment of pain among nursing home residents with cancer at admission by race/ethnicity ( $n=342,920)$

\begin{tabular}{|c|c|c|c|c|}
\hline \multirow[t]{2}{*}{ Pain management and treatment } & $\begin{array}{l}\text { Non-Hispanic } \\
\text { Black } \\
(\mathrm{n}=39,08 \mathrm{I})\end{array}$ & $\begin{array}{l}\text { Non-Hispanic } \\
\text { White } \\
(n=303,839)\end{array}$ & \multirow[t]{2}{*}{$\begin{array}{l}\text { Crude prevalence } \\
\text { ratio }^{a}(95 \% \mathrm{Cl})\end{array}$} & \multirow[t]{2}{*}{$\begin{array}{l}\text { Adjusted prevalence } \\
\text { ratio }^{\text {b }}(95 \% \mathrm{CI})\end{array}$} \\
\hline & \multicolumn{2}{|l|}{ Percentage } & & \\
\hline Any pharmacologic pain management (versus none) & 66.6 & $7 I .1$ & $0.96(0.95-0.97)$ & $0.98(0.97-0.98)$ \\
\hline \multicolumn{5}{|c|}{ Type of pharmacologic pain management (versus no pharmacologic pain management) } \\
\hline Scheduled pain regimen only & 9.0 & 7.8 & $0.99(0.94-1.04)$ & $1.04(0.99-1.10)$ \\
\hline PRN medication only & 34.0 & 37.6 & $0.78(0.76-0.81)$ & $0.84(0.81-0.87)$ \\
\hline Scheduled + PRN & 23.7 & 25.7 & $0.80(0.77-0.83)$ & $0.81(0.78-0.84)$ \\
\hline $\begin{array}{l}\text { Non-pharmacologic pain management (versus no non- } \\
\text { pharmacologic pain management) }\end{array}$ & 25.8 & 34.0 & $0.95(0.94-0.97)$ & $0.98(0.96-0.99)$ \\
\hline
\end{tabular}

Notes: aPrevalence ratio estimated via robust Poisson models with facility clustering accounted for by generalized estimating equations (GEE), and with non-Hispanic Whites as the reference group. For "type of pharmacologic pain management (versus no pharmacologic pain management)," prevalence ratio estimated via a four-level outcome variable in a multinominal logistic model with facility clustering and no pharmacologic pain management as the reference group. ${ }^{b} \mathrm{Adjusted}$ prevalence ratios with non-Hispanic Whites as the reference group derived from models including all characteristics in Table I except variables for receipt of skilled nursing care and source of admission.

Abbreviation: PRN, pro re nata.

documented than non-Hispanic White residents. Regardless of documentation source, non-Hispanic Black residents were less likely to receive pain management than non-Hispanic White resident in nursing homes.

Our findings are consistent with the published literature. ${ }^{7,37,38}$ Previous studies have shown an underreporting of pain among minority races, including African-Americans in US nursing facilities. ${ }^{7,8,38,39}$ One study found that Black nursing home residents were $20 \%$ less likely to have documented daily pain that was at times excruciating when compared with White residents. ${ }^{8}$ Among nursing home residents with cancer, we previously found that African-Americans were $45 \%$ less likely to have documented daily pain compared with that of White residents using 1990 data from the MDS 2.0. ${ }^{7}$ A more recent study by our group reported similar trends. ${ }^{1}$ While only these 2 studies have reported pain management according to race/ethnicity among nursing home residents with cancer, both results parallel our current findings. Using the MDS 2.0, we also previously showed that African-Americans had a $63 \%$ higher probability of receiving no analgesics as documented on the MDS among those with daily pain compared with Whites. In a study using data from 2006 to 2007, we observed similar patterns. ${ }^{1}$ Using more recent MDS 2.0 data cross-linked to pharmacy transaction data, we noted a trend that non-Hispanic Blacks were less likely to receive any analgesic for any pain compared with non-Hispanic Whites.

The potential mechanisms behind the racial disparities in pain reporting and management that were observed in our study and others could stem from facility- or provider-level bias in reporting and perceptions of pain. ${ }^{16}$ At the facilitylevel, several studies have shown that African-Americans are more likely to be at lower quality nursing homes than their non-Hispanic White counterparts. ${ }^{40,41}$ If African-Americans are more likely to be at these lower quality nursing homes, it is understandable that their pain reporting and management would be affected since lower quality facilities would have fewer medical personnel and less administrative resources available. In addition, it has been shown that nursing facilities with less hospice staff are more likely to have residents with incomplete pain assessments and less documentation of pain than facilities with more hospice personnel (likely from ascertainment bias). ${ }^{38}$ If lower tiered facilities have less hospice staff and a higher proportion of African-American residents, then the underreporting of pain (and consequently less pain management) among non-Hispanic Blacks could be the result of this phenomenon. At the provider-level, there are 3 types of potential miscommunication between the patient and provider that could affect pain reporting and management: 1) misinterpretation of a patient's expression of pain through discrimination (i.e., biases, prejudices, and stereotyping), 2) language barriers and health literacy, and 3) unintentional intimidation. ${ }^{16}$ Two studies have shown that minority patients participate less in their medical decision making than their non-Hispanic White counterparts. ${ }^{42,43}$ This discrepancy in medical decision making could lead to less communication in pain reporting and worse outcomes in pain management for minority patients. Recent research has linked higher levels of pain to decreased adaption and acceptance of illness. ${ }^{44}$ Furthermore, a recently published review ${ }^{14}$ demonstrated that physicians often have a less positive view of minority patients..$^{14}$ Consequently, minority patients may feel intimidated and be less likely to express an accurate level of their pain to health care providers when compared with non-minority patients. Alternately, providers may be less attuned to recognizing pain in minority patients, or may ascribe expressions of pain to other explanations. Even "self- 
reported" pain is recorded on the MDS 3.0 by care providers, thus implicitly biased racial filtering of the documentation of pain may occur when recording self-reported pain.

We recognize that these findings relate to nursing home residents at admission. As such, the findings may more aptly reflect care received outside of the nursing home setting, rather than care provided in the nursing home. While future work will focus on racial differences in pain over the course of the nursing home stay, our findings have important implications. First, that such differences extended to residents admitted to nursing homes should be highlighted. The medically supervised setting that nursing homes provide offers an opportunity to reduce racial disparities in pain recognition and management. Furthermore, all Medicaid- and Medicarecertified nursing homes are required to report facility quality indicators, which include prevalence of pain among residents. These quality indicators are publicly available and can be used to rate and compare facilities. Our findings about differential documentation of pain should be considered when interpreting pain-related quality indicators, given the known racial segregation of nursing homes.

Our results can help to shed light on racial disparities and their potential mechanisms in the management of pain among nursing home residents with cancer, individuals who are particularly susceptible to high levels of pain. To our knowledge, this is the first study to thoroughly evaluate disparities between Blacks and Whites in pain among residents with cancer in US nursing homes using the improved pain measures included on the MDS 3.0. There are some limitations to keep in mind. We assessed residents' pain and its management at admission, pain may be treated differently among longer staying residents. The prevalence of different cancers may not be the same across all racial/ethnic groups. Since some cancer types and stages have higher associations with pain and certain racial/ethnic groups than others, this could have affected the apparent disparity in documented pain. However, we had no information on cancer type and stage. In addition, reports of pain are limited to the data in the MDS 3.0, which asks about pain within the past 5 days. The extent of self-reported pain could be subject to recall bias, especially since many residents in the nursing home have some level of cognitive impairment. The MDS 3.0 only includes basic information about medications for pain, and not specific drugs. The extent to which unequal management of pain persists in nursing homes should be further explored by evaluating specific medications, dosages, longer staying residents, and specific types of cancer.

\section{Conclusion}

This study indicates that there are racial disparities that extend from other health care settings into nursing homes. The improved pain measures in the MDS 3.0 have not eliminated differences in documented pain among newly admitted nursing home residents with cancer. More research should be done to more systematically understand racial disparities in pain reporting and its management among nursing home residents with cancer to help guide targeted interventions. Given the terminal nature of cancer, especially when experienced by an older individual in a nursing home, providing equitable pain management is paramount.

\section{Acknowledgments}

We thank Dr. Robert Goldberg for his editorial guidance. This paper was presented at the 33rd Annual Meeting of the International Conference of Pharmacoepidemiology held in Montreal, Canada, in August 2017. This work was supported in part by the National Institutes of Health (TL1 TR001454 and R21CA198172).

\section{Disclosure}

The authors report no conflicts of interest in this work.

\section{References}

1. Pimentel CB, Briesacher BA, Gurwitz JH, Rosen AB, Lapane KL. Pain management among nursing home residents with cancer. J Am Geriatr Soc. 2015;63(4):633-641.

2. Lanser P, Gesell S. Pain management: the fifth vital sign. Healthc Benchmarks. 2001;8(6):68-70.

3. Drageset J, Corbett A, Selbaek G, Husebo BS. Cancer-related pain and symptoms among nursing home residents: a systematic review. J Pain Symptom Manage. 2014;48(4):699-710.

4. Buchanan RJ, Barkley J, Wang S, Kim M. Analyses of nursing home residents with cancer at admission. Cancer Nurs. 2005;28(5):406-414.

5. Duncan JG, Bott MJ, Thompson SA, Gajewski BJ. Symptom occurrence and associated clinical factors in nursing home residents with cancer. Res Nurs Health. 2009;32(4):453-464.

6. Johnson VM, Teno JM, Bourbonniere M, Mor V. Palliative care needs of cancer patients in U.S. nursing homes. J Palliat Med. 2005;8(2): 273-279.

7. Bernabei R, Gambassi G, Lapane $\mathrm{K}$, et al. Management of pain in elderly patients with cancer. JAMA. 1998;279(23):1877-1882.

8. Teno JM, Kabumoto G, Wetle T, Roy J, Mor V. Daily pain that was excruciating at some time in the previous week: prevalence, characteristics, and outcomes in nursing home residents. J Am Geriatr Soc. 2004;52(5):762-767.

9. Kumar A, Allcock N. Pain in Older People: Reflections and Experiences from an Older Person's Perspective. London: Help the Aged; 2008. Available from: https://www.britishpainsociety.org/static/uploads/resources/ files/book_pain_in_older_age_ID7826.pdf. Accessed October, 2017.

10. Levy MH. Pharmacologic treatment of cancer pain selection of the appropriate analgesic therapy. $N$ Engl J Med. 1996;335(15): 1124-1132. 
11. Zech DFJ, Grond S, Lynch J, Hertel D, Lehmann KA. Validation of world health organization guidelines for cancer pain relief: a 10-year prospective study. Pain. 1995;63(1):65-76.

12. Pergolizzi J, Boger RH, Budd K, et al. Opioids and the management of chronic severe pain in the elderly: consensus statement of an International $/ n E x p e r t$ Panel with focus on the six clinically most often used World Health Organization Step \nIII opioids (buprenorphine, fentanyl, hydromorphone, methadone, morphine, oxycodone). Pain Pract. 2008;8(4):287-313.

13. American Geriatrics Society Panel on Pharmacological Management of Persistent Pain in Older Persons. Pharmacological management of persistent pain in older persons. J Am Geriatr Soc. 2009;57(8): 1331-1346.

14. Maina IW, Belton TD, Ginzberg S, Singh A, Johnson TJ. A decade of studying implicit racial/ethnic bias in health care providers using the implicit association test. Soc Sci Med. Epub 2017 May 4.

15. Kilbourne AM, Switzer G, Hyman K, Crowley-Matoka M, Fine MJ. Advancing health disparities research within the health care system: a conceptual framework. Am J Public Health. 2006;96(12): 2113-2121.

16. Institute of Medicine. Chapter 4: assessing potential sources of racial and ethnic disparities in care: the clinical encounter. In Unequal Treatment. Smedley B, Stith AY, Nelson AR, editors. National Academies Press: Washington, DC, USA; 2002.

17. Johnson RL, Roter D, Powe NR, Cooper LA. Patient race/ethnicity and quality of patient-physician communication during medical visits. $\mathrm{Am}$ J Public Health. 2004;94(12):2084-2090.

18. Green CR, Ndao-Brumblay SK, Nagrant AM, Baker TA, Rothman E. Race, age, and gender influences among clusters of African-American and white patients with chronic pain. J Pain. 2004;5(3):171-182.

19. McDonald DD. Gender and ethnic stereotyping and narcotic analgesic administration. Res Nurs Health. 1994;17(1):45-49.

20. Won A, Lapane K, Gambassi G, Bernabei R, Mor V, Lipsitz LA. Correlates and management of nonmalignant pain in the nursing home. J Am Geriatr Soc. 1999;47(8):936-942.

21. Mossey JM. Defining racial and ethnic disparities in pain management. Clin Orthop Relat Res. 2011;469(7):1859-1870.

22. Cleeland CS, Gonin R, Hatfield AK, et al. Pain and its treatment with outpatient metastatic cancer. N Engl J Med. 1994;330(9):592-596.

23. Green CR, Baker TA, Smith EM, Sato Y. The effect of race in older adults presenting for chronic pain management: a comparative study of black and white Americans. J Pain. 2003;4(2):82-90.

24. Saliba D, Buchanan J, Buchannan J. Development and Validation of a Revised Nursing Home Assessment Tool: MDS 3.0. Centers for Medicare and Medicaid Services: Baltimore, MD, USA; 2008. http://www. geronet.med.ucla.edu/centers/borun/Appendix_A-G.pdf. Accessed October, 2017.

25. CMS. Section I : Active Diagnoses Active Diagnoses in the Last 7 Days I : Active Diagnoses in the Last 7 Days (cont.). 2010;(September): $1-10$.

26. CMS. Section J : Health Conditions J0100 : Pain Management (cont.). 2010;(May):1-33.
27. Edelen MO, Saliba D. Correspondence of verbal descriptor and numeric rating scales for pain intensity: an item response theory calibration. J Gerontol A Biol Sci Med Sci. 2010;65(7):778-785.

28. CMS. Section A : Identification Information A0100 : Facility Provider Numbers A0200: Type of Provider A0310: Type of Assessment. 2010;(July):1-26.

29. Luo H, Zhang X, Cook B, Wu B, Wilson MR. Racial/ethnic disparities in preventive care practice among U.S. Nursing home residents. J Aging Health. 2014;26(4):519-539.

30. Morris JN, Fries BE, Morris SA. Scaling ADLs within the MDS. J Gerontol A Biol Sci Med Sci. 1999;54(11):M546-M553.

31. Thomas KS, Dosa D, Wysocki A, Mor V. The Minimum Data Set 3.0 Cognitive Function Scale. Med Care. 2017;55(9):e68-e72.

32. Zeitz J, Ak M, Müller-Mottet S, et al. Pain in IBD patients: very frequent and frequently insufficiently taken into account. PLoS One. 2016;11(6):e0156666.

33. Rana AQ, Kabir A, Jesudasan M, Siddiqui I, Khondker S. Pain in Parkinson's disease: analysis and literature review. Clin Neurol Neurosurg. 2013;115(11):2313-2317.

34. Foley PL, Vesterinen HM, Laird BJ, et al. Prevalence and natural history of pain in adults with multiple sclerosis: systematic review and meta-analysis. Pain. 2013;154(5):632-642.

35. Coutinho LM, Scazufca M, Menezes PR. [Methods for estimating prevalence ratios in cross-sectional studies]. Rev Saúde Pública. 2008;42(6):992-998. Portuguese.

36. Zou GY, Donner A. Extension of the modified poisson regression model to prospective studies with correlated binary data. Stat Methods Med Res. 2013;22(6):661-670.

37. Teno JM, Gozalo PL, Bynum JP, et al. Change in end-of-life care for medicare beneficiaries: site of death, place of care, and health care transitions in 2000, 2005, and 2009. JAMA. 2013;309(5):470-477.

38. Wu N, Miller SC, Lapane K, Gozalo P. The problem of assessment bias when measuring the hospice effect on nursing home residents' pain. J Pain Symptom Manage. 2003;26(5):998-1009.

39. Pimentel CB, Gurwitz JH, Tjia J, Hume AL, Lapane KL. New initiation of long-acting opioids in long-stay nursing home residents. $J \mathrm{Am}$ Geriatr Soc. 2016;64(9):1772-1778.

40. Mor V, Zinn J, Angelelli J, Teno JM, Miller SC. Driven to tiers: socioeconomic and racial disparities in the quality of nursing home care. Milbank Q. 2004;82(2):227-256.

41. Smith DB, Feng Z, Fennel ML, Zinn JS, Mor V. Separate and unequal: racial segregation and disparities in quality across U.S. nursing homes. Health Aff (Millwood). 2007;26(5):1448-1458.

42. Cooper-Patrick L, Gallo JJ, Gonzales JJ, et al. Race, gender, and partnership in the patient-physician relationship. JAMA. 1999;282(6):583-589.

43. Kaplan SH, Gandek B, Greenfield S, Rogers W, Ware JE. Patient and visit characteristics related to physicians' participatory decisionmaking style. Results from the Medical Outcomes Study. Med Care. 1995;33(12):1176-1187.

44. Chabowski M, Junke M, Juzwiszyn J, Milan M, Malinowski M, Janczak D. Adaptation to illness in relation to pain perceived by patients after surgery. J Pain Res. 2017;10:1447-1452. 


\section{Supplementary material}

Table S Minimum Data Set (MDS) 3.0 item numbers for nursing home resident characteristics assessed

\begin{tabular}{|c|c|}
\hline Characteristics assessed & MDS Item \\
\hline Pain items & J0200, J0300, J0800 \\
\hline Pain management items & J0I00A, B, C \\
\hline Age & A0900 \\
\hline Women & A0800 \\
\hline Race & Al000 \\
\hline Married & $\mathrm{A} \mid 200$ \\
\hline Receiving skilled nursing care & A0310 \\
\hline Source of admission & Al800 \\
\hline Rejects care & E0800 \\
\hline Hospice use & OOIOOK \\
\hline Six month or less prognosis & JI400 \\
\hline Activities of Daily Living & G0II0 \\
\hline Cognitive impairment & $\mathrm{C} 0300-\mathrm{Cl} 1000$ \\
\hline Heart failure & 10600 \\
\hline Respiratory failure & 16300 \\
\hline Inflammatory bowel disease & 11300 \\
\hline Arthritis & 13700 \\
\hline Osteoporosis & 13800 \\
\hline Fracture (hip and other) & 13900,14000 \\
\hline Skin lesions/infections/ulcers & M02I0, M0300 \\
\hline Parkinson's disease & 15300 \\
\hline Multiple sclerosis & 15200 \\
\hline
\end{tabular}

Abbreviation: MDS, minimum data set.

The Journal of Pain Research is an international, peer reviewed, open access, online journal that welcomes laboratory and clinical findings in the fields of pain research and the prevention and management of pain. Original research, reviews, symposium reports, hypothesis formation and commentaries are all considered for publication.

\section{Dovepress}

The manuscript management system is completely online and includes a very quick and fair peer-review system, which is all easy to use. Visit http://www.dovepress.com/testimonials.php to read real quotes from published authors. 